\title{
O GALEGO NO TEATRO DOS XESUITAAS EN GALICIA (1572-1729)
}

Julio I. González Montañés Centro EPA (Pontevedra)

DOI: 10.17075/cbfc. 2020.011 



\section{OS XESUÍTAS E O TEATRO}

Pouco tempo transcorreu dende a fundación da Compañia de Xesús por Ignacio de Loiola en 1540 ata a decisión de orientar o labor da nova orde cara ao ensino e a educación. En apenas cen anos, os xesuítas espallaron por case toda Europa e por boa parte de América unha rede de centros de ensinanza que, no caso de Galicia, converteu a Compañía na principal institución dedicada ao ensino secundario ${ }^{1}$.

De contado os discípulos do de Loiola decatáronse das posibilidades do teatro como vehículo de transmisión do seu programa moralizante e evanxelizador, como aparato propagandístico ao servizo da expansión da Compañía, e como recurso didáctico que, prodesse et delectare, podía ser moi útil como exercicio literario e retórico para alumnos e profesores, e como necesario contrapunto lúdico e festivo do estudo.

Aínda que na Ratio Studiorum que regulaba a ensinanza dos colexios se ordenaba que as representacións se fixeran só en ocasións moi sinaladas, sempre

1 A presenza dos discípulos de San Ignacio de Loiola en Galicia foi temperá; tres Padres, procedentes de Braga, estaban en Santiago en 1543, só tres anos despois da fundación da orde. En 1544 chegaron doce, procedentes de Lovaina, ata A Coruña onde predicaron con grande éxito uns días antes de seguir cara a Coimbra. Temos tamén noticias dunha misión xesuíta en Mondońedo en 1547, e sabemos que en Compostela intentaron, en 1551-1552, facerse cargo do control do Colexio de Fonseca e, a través del, de toda a Universidade, entón en proceso de reestruturación e consolidación como institución académica. Os xesuítas contaron en Santiago co apoio do arcebispo Álvarez de Toledo e do conde de Monterrei, Don Alonso de Acevedo e Zúńiga, testamenteiros do arcebispo Don Alonso de Fonseca, fundador do colexio compostelán. Álvarez de Toledo era amigo persoal de San Ignacio, ao que encargou unha reforma do plan de estudos que o santo enviou en 1552, aínda que non chegou a entrar en vigor pola forte oposición do concello que "no quería un Colegio sino una Universidad honrada", e do claustro, dominado polos beneditinos e os dominicos, que solicitaron a intervención real. Como compensación por este fracaso, o conde de Monterrei fundou e dotou en 1555 un colexio da orde na súa vila natal, o primeiro dos que tiveron os xesuítas en terras galegas, seguido nas décadas seguintes polos de Compostela (1577) e Monforte (1593) e, xa no século xviı, polos de Ourense (1653-1654), Pontevedra (1655) e A Coruña (1673), ademais do caso especial do Colexio dos irlandeses de Compostela, dirixido polos xesuítas dende 1613. 
en lingua latina e sobre temas piadosos, pronto medrou a frecuencia destas, ampliouse a súa temática, complicouse a escenografía e introducíronse nelas as linguas vernáculas (en España antes que no resto de Europa). A razón destes cambios estaba no desexo de chegar a un público máis amplo que o escolar, xa que as representacións se facían con asistencia dos familiares dos alumnos, das autoridades locais, eclesiásticos e pobo en xeral. Non eran simples actos académicos; tamén o foron sociais, e en Galicia sen dúbida contribuíron a familiarizar a sociedade da época co feito teatral.

No caso galego, puiden reunir, no período que vai dende 1558 ata 1710 , noticias de 32 representacións teatrais nos colexios xesuítas de Monterrei (17), Monforte (6) e Santiago (9) ${ }^{2}$. A elas pódenselles engadir dous ou tres casos dubidosos, documentados soamente pola existencia dos textos teatrais nas bibliotecas colexiais, e un par de pezas de autores xesuítas representadas en Galicia pero fóra dos colexios da orde ${ }^{3}$, como a Loa que se escenificou en Ourense en 1707 nos festexos polo nacemento do príncipe Luis Fernando (o futuro e efémero Rei Luís I $)^{4}$, ou a Loa a la dedicación del nuevo camarín de Nuestra Señora de las Hermitas do Padre galego Luis de Losada (1729), que teño intención de publicar proximamente.

A documentación conservada proporciona na maioría dos casos o título da peza representada e a súa data, e, en moitos deles, noticias sobre a escenografía, o público asistente e a repercusión social que tiñan as representacións. Os textos conservados son, pola contra, escasos: ademais das dúas Loas xa mencionadas, cońécese o texto dalgunha das pezas castelás de autores xesuítas famosos que se representaron en colexios galegos (a Comedia Margarita do Padre Juan Bonifacio

2 A maioría delas son do século Xvı, e a máis antiga, a das Comoediae atque tragediae representadas en Monterrei en 1558. Véxase a miña base de datos na internet (González Montañés 2014).

3 Un caso especial é o do gramático e astrólogo irlandés Patricio Synnot, relacionado co Colexio dos irlandeses de Compostela, e xesuíta segundo Emilio González López, que foi rexente de Artes na Universidade de Santiago e autor da comedia que se representou no pazo de Fonseca o 21 de maio de 1619 nas festas de Pascua de Pentecoste (Arquivo Histórico Universitario de Santiago, sig. A-114, Libro de Claustros de 1610 a 1622, fols. 432r-433 e 437v). Por outra parte, a figura de Synnot ten certa importancia na historia do teatro galego xa que é o protagonista da peza de Luís Seoane $O$ irlandés astrólogo (1959).

4 O texto da peza, obra probablemente do xesuíta galego Luis de Losada, recóllese no relato impreso dos festexos ourensáns (El Clarín de la fama..., pp. 74-94), no cal aparecen algúns poemas que poderían ser tamén da pluma de Losada como as Coplas al principe Luis (pp. 97-98) ou os Versos gallegos a nuestra Señora de Reza (pp. 179-180). 
en Monforte en 1619, por exemplo), e tamén o dun par de pezas anónimas moi frecuentes no teatro colexial peninsular que probablemente se representaron en Monterrei: o Diálogo para la elección de un emperador (+ 1585) e o Coloquio de las Letras y las Armas (ca. 1680).

Polo que se refire aos textos producidos en Galicia e representados en colexios galegos, na última década atopáronse tres, e penso que hai que sumarlles o Entremés del portugués, publicado en 1985 por José Luis Pensado, obra con case total seguridade xesuíta, de autor galego e representada probablemente en Monterrei en 1710. A peza máis antiga conservada é o Diálogo de la Concepción de Nuestra Señora representado en Monterrei en 1578 (cfr. Pascual Barea 2009), seguida pola Égloga de Virgine Deipara, tamén de Monterrei (1581), a Comedia de la invención de la sortija (Monforte, 1596) e o Entremés del portugués citado (1710).

\section{O GALEGO NOS COLEXIOS DE GALICIA}

Da documentación conservada dedúcese a existencia, por parte dos membros da orde xesuíta, dunha actitude que hoxe cualificariamos de colonialista diante da "gente tan inculta como bárbara" e "tan remota de toda disciplina" do Reino de Galicia, á cal chegan a comparar con "gentiles e idólatras"'. Tampouco podemos esquecer que ao Padre aragonés asentado en Galicia, J. A. Butrón y Múxica, se debe unha das máis crueis sátiras contra Galicia das que temos noticias nesa época, e son moitas ${ }^{6}$, pero hai que ter en conta que a maior parte das noticias proceden de cartas Annua e Quadrimestres, informes que os rétores dos colexios galegos enviaban periodicamente a Roma e nos que sempre, especialmente nos

5 Carta dende Monterrei do Provincial P. Gil González Dávila a Francisco de Borja en Roma (12/07/1569), ARSI, Fondo xesuitico 1469/2, n. ${ }^{\circ}$ 40; relato de Diego Jiménez secretario do visitador P. Nadal o 4 de maio de 1561 (Epistolae P. Hyeronimi Nadal Societatis Jesu ab anno 1546 ad 1577, En: MHSI, Typ. Agustini Aurial, Madrid, 1898, vol. I, p. 452), e informe do Padre salmantino Martín de Santo Domingo, misioneiro polas parroquias rurais galegas a finais do século XVI (ARSI, Castellana 35 II, fol. 440v, apud Cabada Castro 2015: 19).

6 Descripción del Reino de Galicia (ca. 1701), escrita en hendecasílabos encadeados e conservada en media ducia de manuscritos, proba da súa popularidade (véxase Busto Cortina 2015: 53-55); o texto do Ms. 3705 da BnE (fols. 1-8) foi publicado por Cristóbal Hornillos (2010: 111-120). Malia a súa galegofobia, que se manifesta tamén noutros poemas do autor, como as Décimas de Góngora, na edición dos festexos ourensáns de 1707 Butrón inclúe un poema en galego á Virxe de Reza, atribuído a José Noguerol e Camba pero obra, creo, do P. Luis de Losada (Butrón y Múxica / Cossío Bustamante 1708: 179-180, 214). 
dos primeiros tempos, se compracen en destacar o celo educador dos Padres e os seus éxitos na alfabetización e na reforma dos costumes dos bárbaros e idólatras de Galicia?.

Porén, hai tamén loanzas, por exemplo aos nenos de Compostela, que en 1597, apenas un ano despois da apertura do colexio, foron quen de representar unha Comedia sobre la Eucaristía con asistencia de moito público e do arcebispo, e que "arrancaron el aplauso y la admiración general al comprobar el fruto que en sólo un año han alcanzado". Naturalmente, a mención pode entenderse como un autoeloxio do reitor que escribe a Annua, mais o de Monterrei non dubidaba en recońecer en 1565 que "es admirable la facultad que tienen los estudiantes de este reino para escribir".

Parece que houbo de todo e non hai que deixarse enganar polas Litterae, sempre exaxeradas. O colexio de Monterrei, por exemplo, espertou a admiración dos xesuítas de toda España polo grandísimo número de alumnos, sorprendente nunha vila de pouco máis de 100 habitantes (chegaron a 1300 en 1589, cando Sevilla tiña 1000), e nas súas aulas impartiron docencia boa parte dos mellores profesores da Compañía, polo que non pode estañar que a III Condesa de Monterrei, Dona Inés de Velasco, decidira en 1572 instalarse na vila "porque también gozasen sus hijos del fruto común, crianza y enseñanza deste collegio de que gozaban los hijos de sus vasallos", ou que os condes de Lemos educaran os seus fillos no colexio monfortino.

Nos primeiros tempos os xesuítas tiveron problemas de adaptación, e o fracaso do seu intento de converter a Universidade de Santiago nun colexio fíxolle dicir ao P. Díaz "que lo que más tenía necesidad [Galicia] era de costumbres y no de leyes ni cánones, que hartas universidades había buenas para esto”. Con todo, o P. Jerónimo Nadal escribiu en 1556 a San Ignacio dicíndolle: "Es menester, Padre, gran tiento, según veo, en tratar con gallegos”, e parece que os Padres,

\footnotetext{
7 As principais fontes para o estudo dos xesuítas en Galicia son as Litterae Annua e Quadrimestres conservadas no arquivo romano da Compañía (ARSI), e as historias do Padre Pedro de Guzmán (Memorias de la fundación de los Colegios de la Provincia de Castilla, de finais do século XvI) e do Padre Luis de Valdivia (Historia de los Colegios de la Provincia de Castilla, ca. 1604), quen nunca pisou Galicia e, para o caso de Monterrei, utiliza os datos da Historia del Colegio de Monterrey do P. Diego de García (Ms. 478 do Arquivo Histórico Provincial de Ourense). Todas elas foron empregadas por Evaristo Rivera Vázquez (S. J.) nunha obra que segue sendo imprescindible para achegarse ao estudo do xesuitismo en Galicia (Rivera Vázquez 1989).
} 
superado o choque cultural inicial, acabaron aceptando que "la tierra de Galicia es diferente en muchas cosas a la de Castilla y el quererla reducir a las mismas co-

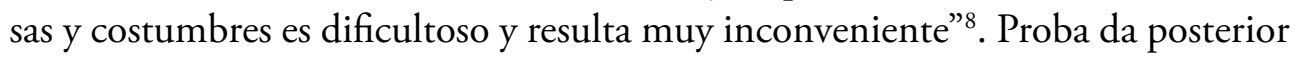
integración da Compañía en Galicia é o uso do galego no seu teatro e certames literarios, ou o feito de que tres xesuítas galegos escribiran Historias de Galicia, e dende unha perspectiva patriótica ${ }^{9}$.

Sabemos que a maioría dos reitores e profesores ata finais do século XVII eran foráneos, e que, nos primeiros tempos, maiormente os Padres non querían vir a colexios galegos, que para eles eran unha sorte de desterro, ou pedían vir pero como quen vai a terra de misión, a unha nova India ${ }^{10}$. Malia iso, prestóuselle certa atención á lingua galega e consta, xa en 1572, que con motivo dunha celebración polo traslado dos restos mortais do conde de Monterrei, fundador do colexio, dende Santiago á súa vila natal, os profesores e estudantes redactaron "papeles de varias composiciones [...], en verso y prosa, en lenguas latina, griega, hebrea, española, gallega y portuguesa [...], de que estaba cubierta toda la yglesia"11.

Rivera Vázquez afirma, partindo deste dato, que o colexio de Monterrei era un estudio políglota no que se falaba latín, castelán e galego ${ }^{12}$ (e portugués, hai que supoñer), e tanto o Diálogo de la Concepción de Nuestra Señora como a Égloga de Virgine Deipara confirman a súa apreciación, xa que no primeiro se utiliza o latín e o castelán, en na Égloga, latín, castelán, portugués e galego.

Hai tamén indicios do uso do galego no colexio de Santiago de Compostela. Non consta o seu emprego nas representacións teatrais, pero sabemos que o gramático Juan Antonio Torrado presentou un romance en galego ao certame das

8 Iso foi o que lle dixo Baltasar de Zúńiga, educado no colexio de Monterrei, á súa nai Dona Inés, desesperada pola resistencia dos colexiais monfortinos a aceptar as Ordenanzas que pretendía impońer.

9 Historia de Galicia [manuscrita] do P. Benito Vázquez (mediados do século XvII); Historia general del Reino de Galicia [manuscrita] do P. Juan Álvarez Sotelo (principios do século XvIII), e Galicia Reyno de Christo Sacramentado, y primogénita de la Iglesia entre las gentes..., do Padre P. Fernández de Seguín (Imp. del Nuevo Rezado, México, 1750).

${ }^{10}$ En 1561 o secretario do P. Nadal escribe: "Se hace tal fruto que los Padres y Hermanos que aquí están, dicen que tienen aquí otra India"; Gaspar de Ávila fala de "estas Indias de Dios", e o segundo Padre Xeneral da Compañía, o soriano Diego Laínez, díxolle en 1563 ao reitor de Monterrei P. Juan Bautista Segura que quería marchar ás Indias de misioneiro: "No será poca India la que tienen en Galicia”.

${ }^{11}$ Valdivia, Luis de, Historia de los Colegios de la Provincia de Castilla, cap. 3. Edición en Valdivia (1932: 353).

${ }^{12}$ Rivera Vázquez (2006: 36). O Padre Rivera achegou nos seus traballos moitísimas noticias sobre representacións teatrais nos colexios galegos, pero non coñeceu o texto de ningunha das obras representadas. 
Fiestas Minervales compostelás de $1697^{13}$, e parece probable que os xesuítas, moi implicados na organización das festas que se fixeron en Santiago en 1713 pola canonización de San Pío V, fosen autores dalgúns dos versos gallegos que, escritos en carteis e acompañados doutros en castelán e en italiano, engalanaron un dos corredores do claustro de S. Domingos de Bonaval (cfr. Pacheco y Troncoso 1715: 51).

Xesuíta tamén, e probablemente galego aínda que escribira fóra de Galicia, foi o autor do Romancillo da cea do cordeiro (ca. 1680) conservado nun volume misceláneo manuscrito da Biblioteca Nacional, e dado a cońecer Rosario Álvarez Blanco e Ernesto González Seoane (2015).

Temos tamén casos documentados de profesores dos colexios galegos que escribiron obras de teatro, hoxe perdidas, como Antonio Rodríguez (finais do século Xvi), natural de Vilaza (Monterrei), o cal, segundo o Padre Valdivia, "tenía gracia particular en hacer coloquios y representaciones santas y andanzas muy graciosas en nuestras fiestas; y componía unos entremeses muy graciosos y honestos con que alegraba a las innumerables gentes que acudían a nuestras fiestas en Carnestolendas" 14 .

Galego, aínda que non exerceu a docencia en Galicia, foi tamén o Padre Luis de Losada e Prada (1681-1748), autor documentado da Loa das Ermidas e probable do Entremés del Portugués. Este último está escrito maioritariamente en galego e portugués, e, agás no Diálogo de la Concepción de Nuestra Señora, nas restantes pezas galegas conservadas atópanse partes e incluso escenas completas en galego.

\section{OS TEXTOS}

Na Egloga de Virgine Deipara de Monterrei (1581), que dei a coñecer e editei parcialmente nalgúns dos meus traballos (González Montañés 2007, 2008; cfr.

${ }^{13}$ Fiestas Minervales, y aclamación perpetua de las Musas..., pp. 49-52. Torrado aparece no impreso como Gramático, o cal parece indicar que era ou fora alumno do Colexio da Compañía, pero non consta que fose xesuíta e non figura nos Catalogus Defunctorum da orde.

${ }^{14}$ Valdivia, Luis de (S. J.), Vida de algunos varones ilustres de la provincia de Castilla (Ms., 82 fols.). Copias en: Archivum Romanum Societatis Iesu (ARSI) y Archivo Histórico de la Provincia de Toledo de la Compañía de Jesús (AHSJPT, dende 2015: Archivo de España de la Compañia de Jesús - Alcalá de Henares (AESI-A), leg. 1702 (a cita no fol. 415). 
ademais Alonso Asenjo 2018), hai extensos diálogos nos que Lusitanus fala en portugués trasmontano, e nela aparece tamén un himno final [Ms., fol. $42 \mathrm{v}$, col. b] en galego relativamente correcto, aínda que con lusismos (Philippo, nem) e castelanismos $(\mathrm{No})$, probablemente debidos a vacilacións do autor ou do copista, comprensibles e frecuentes nunha época na que non existían modelos de escrita en galego, e nun manuscrito copiado probablemente en Madrid:

\author{
Viva, viva, viva \\ o Philippo en Portugal. ${ }^{15}$ \\ Castela e Galicia, ${ }^{16}$ \\ con grande irmandad. \\ Vivan os galegos \\ e os castelaos, \\ co os lusitanos \\ seglares e cregos. \\ No aja mays renegos \\ nem guerra, ne afán. ${ }^{17}$
}

No caso da Comedia de la invención de la sortija representada en Monforte en outubro de 1596 co gallo da visita á localidade do fundador e mecenas do colexio, o cardeal D. Rodrigo de Castro, inclúense na representación, que se fixo en dúas xornadas, unha serie de Entremeses e, no denominado Entremés de los pajes y Quinolilla, unha das escenas está composta integramente en galego, constituíndo un paso ou semientremés que, como os seus editores propoñen, podería titularse Entremés de Janiño y los pastores ${ }^{18}$.

\footnotetext{
${ }^{15}$ Ao final deste verso, e despois de punto, o copista escribe: en[]Por[tugal] etc., o cal, tendo en conta que é un texto para cantar, parece indicar que un coro repetía como eco os versos.

${ }^{16}$ Ao final deste verso, e despois de punto, o copista escribe: Caste[la] etc.

${ }^{17}$ Ao final deste verso, e despois de punto, o copista escribe: Cast[ela] etc.

${ }^{18} \mathrm{O}$ texto manuscrito desta peza, procedente probablemente dos arquivos dos Condes de Lemos, consérvase na Fernán Núnez Collection da Bancroft Library na University of California en Berkeley (UCB Ms. 143, vol. 18 [D-2]). Mencionada nos catálogos impresos da devandita biblioteca, transcribiu algúns versos dela José I. Díez Fernández en 1997, e a escena en galego editouna en 2001 o profesor da UCB Antonio Cortijo Ocaña. Recentemente, Antonio Cortijo e Miguel Zugasti publicaron unha edición completa e un estudo da obra: Cortijo Ocaña / Zugasti Zugasti (2016).
} 
Nel interveñen tres pastores (Pascual, Afonso e Pelaio) que queren emborrachar ao tamborileiro Janińo, e acaban todos cantando e bailando. Saen deseguido as cidades e estados de Galicia a pedir que se corra a sortija, entréganse os premios e conclúe así a primeira xornada da festa-representación. O texto desta escena cómica de 55 versos, que hai que supoñer de autor galego, é o seguinte:

Pastor 1..$^{\circ}$ (Afonso): $\quad$ Vimos, si a Deus lle prougo, e con moito do contento.

Pastor 2. (Pascual): $\quad$ ¡Ola, Afonso! ¿O Cardenal é crego?

Pastor 1.` (Afonso): $\quad$ ¡E máis que crego! ¿Pois no no sabes, Pascual?

Pastor 2..$^{\circ}$ (Pascual): $\quad$ No no sei, ipor sant Jamego!

Pastor 1..$^{\circ}$ (Afonso): $\quad$ Si, y aón o noso natural

Pastor 2. (Pascual): ¿ ¿Que crego vos é de misa?

Pastor $1 .^{\circ}$ (Afonso): $\quad$ Si.

Pastor 2..$^{\circ}$ (Pascual): $\quad$ Pois respondeime, Pelayo, ¿por que trai a camisa vestida en riba do sayo, qui é, par Deus, cousa de risa?

Pastor $3 .^{\circ}$ (Pelaio): $\quad$ ¡Cala, tolo! ¿Diz por quei?

Seméllase a non sei quei.

Pastor 1. (Afonso): $\quad$ Traiéna os arçobispos descuberta y os bispos. 
Pastor 2..$^{\circ}$ (Pascual): $\quad$ Perdónenme si pequei;

y o bonete colorado

que a cabeça lle toma,

¿é por andar arroupado?

Pastor 1.․ (Afonso): $\quad$ Non, sinón que veu de Roma

co'aquil cardenalado.

Aqui se tañe un tamborino dentro.

Pastor 3. ${ }^{\circ}$ (Pelaio): $\quad$ Pascual y Afonso, escoitai,

porque o tamboril ja sona.

$\mathrm{O}$ vino á présa sacai

e fagamos una mona

a Janiño .

Entra Janiño con su tamborino.

Janiño:

¿Qué se fai?

Pastor 1. ${ }^{\circ}$ (Afonso): $\quad ¡$ Ay, Afonso, saca a bota!

Juro a meus que has de beber.

Janiño:

Que no me facía mester.

Pastor 1. (Afonso): $\quad$ Fártate, non deijes gota,

um cuartal lo ha de fazer.

Janiño:

Vós, ¿d'onde demo topastes

co o bon?, ¿'no mercado?

Pastor 1. ${ }^{\circ}$ (Afonso): $\quad$ Non, sinón en cas de Sobrado. 
Janińo:

Pastor 3. ${ }^{\circ}$ (Pelaio):

Janiño:

Pastor 1. ${ }^{\circ}$ (Afonso):

Janińo:

Pastor 2. ${ }^{\circ}$ (Pascual):

Janiño:
¡Voto a meus que acertastes, qu'el é bon e regalado!

¡Ay, Jan, cata! Non te enfermes nen sentencies con malicia. Cata, que a y-alma perdes.

Andai, qu'eu farei justicia.

Calai e bailai si souberdes.

Vosoutros, no me fagás

me hispá, porque vos juro

co demo non faga mais.

¡Començai! ¿Non començaas?

Pois tangei, porque sai Lugo.

Entran las mudanzas de zapatear el villano, que fueron cuatro.

(Desafia) Pois agarda, qu'eu farei diabruras. Tangei a compás, que quer bailar Fierabrás.

A todos vos ganarei

si eu començo, e por demais.

Tánenle y hace solo todo cuanto bueno sabe.

Semellante carácter cómico teñen os 71 versos que pronuncia o Gallego no Entremés del portugués. No meu estudo sobre a peza (González Montañés 2016), penso que demostrei que se trata dunha obra xesuítica e propuxen, como hipótese, atribuírlle a súa autoría ao Padre galego de Quiroga, afincado en Salamanca, 
Luis de Losada (1681-1748). Habería que facer, para confirmalo, unha análise comparativa por especialistas entre o texto do Entremés e a restante produción literaria cońecida de Losada, especialmente da teatral. Eu, pola miña parte, só sinalo que a versificación, a comicidade, a caracterización dos personaxes, e o uso da música e as cancións coinciden con outras obras teatrais de Losada.

Parece claro que o Entremés del portugués se representou en Galicia, probablemente no colexio de Monterrei, e as referencias no texto a Bernardo del Carpio cadran coa demostración que fixo o P. Losada antes de morrer de ter aprendido de memoria na súa infancia o poema sobre as súas fazañas (Yebra 1748: 5). Losada menciona tamén a Bernardo del Carpio na Loa a D. Felipe Gil Taboada, e a voz galega $M e c o$, utilizada nun sentido despectivo, aparece tanto no Entremés coma nun poema satírico de Losada contra o frade bieito pontevedrés Juan Antonio Haro, catedrático de teoloxía en Salamanca, que se opoñía á alternancia de cátedras pretendida polos xesuítas ${ }^{19}$.

Hai pouco fixen unha edición anotada do texto do Entremés (González Montañés 2016), polo que aquí limítome a reproducir algúns fragmentos dos parlamentos do galego e a copla cantada final:

$$
\begin{aligned}
& \text { Eu solles de junto Ourense } \\
& \text { máis acá de Santiajo, } \\
& \text { e véńolles de Castilla, } \\
& \text { e véńolles muy cansado, } \\
& \text { e ya non lles podo andar } \\
& \text { con tanto zango e remango. } \\
& \text { Si me deiran de beber } \\
& \text { dixérales como me chamo, } \\
& \text { como se chaman meus pais } \\
& \text { e meus avós todos catro, }
\end{aligned}
$$

19 "Haro, entre frases pomposas, / ¿Qué será? Gallego en suma, / que en borbollones de espuma / suele articular ventosas. / Con embestidas ruidosas, / su golpe es débil y flaco; / buen hijo de Meco y Caco, / cuyo primor, cuya gala, / es ser mosquetón sin bala y ser pólvora sin taco" (apud Cortina Iceta 1981: 148-149). Menciona tamén Losada ao Meco en 1706 no seu panfleto a prol de Filipe V, El Desengaño a cargas, conducido a los sebastianistas: "que [os galegos] por su Rey, y sus nabos, han de renegar de Meco". Parece que Losada lembra o Meco da súa localidade natal da Ermida, máscara demoníaca-festiva que aínda hoxe sae cos xigantes (pampónigas ou pampórnigas) na procesión da Virxe dos Remedios. 
que lles eran christiaos vellos

por tudos catro custados

[...]

E pois déixenme sentar

que lles estoy muy cansado.

Denme una fungaradiña.

[...]

Diganme agora que queren, que do que for preguntado ei de decir a verdade.

[...]

Pois non me atrevo a escoller

que lles hé muy ruin ganado;

e o mellor de todos elles

é o que está aquí sentado.

[...]

Morran eles moitas moscas

que naon veño confesado:

Arrédrense para lá

que vay da riba estirado

o pao da minha fouciña,

e matarei con gran garbo

co a primeira pancada

o que for desvergonzado.

Chéguese acá o portugués,

afora, afora que o mato.

[Canción: "con la tonada de los portugueses"]

Non se pońa conmigo

ningún gabacho,

que se non o meu cinto

a fe que é pardo. 
O Padre Luis de Losada foi tamén o autor, neste caso con total seguridade, dunha peza teatral representada en 1729 no santuario da Virxe das Ermidas (O Bolo, Ourense). A obra, conservada nun manuscrito da Biblioteca Nacional (Ms. 14518/37), e titulada Loa a la dedicación del nuevo camarín de Nuestra Señora de las Hermitas, está escrita practicamente na súa totalidade en castelán, pero os romeiros portenses ${ }^{20}$ que interveñen nela entran en escena entoando unha cantiga en galego. Tres cuartetas que documentan un novo texto poético pertencente aos Séculos Escuros.
Miña Virgen das Hermitas
que está naqueles barrancos, parece unha pastorcińa
co seu cordeyro nos brazos.
O camiño das Hermitas, que vay por aquela costa, vay estreyto, e costa arriba, como o camińo da Groria. $\mathrm{O}$ Vivey, porque non pode subir algo mays arriba, vay chorando, e por debayxo fuxen as augas corridas.

Losada utilizou tamén o galego, ademais de no Entremés del Portugues, aceptando que é obra súa, nas endechas da Oración fúnebre que o colexio da Compañía de Salamanca fixo publicamente como expresión de dor polo pasamento do Rei Luís I en 1724, obra igualmente máis que probable do quirogués (Mariño Paz / Suárez Vázquez 2012). Son, polo tanto, dous textos moi probables e un

${ }^{20} \mathrm{O}$ xentilicio portenses, e as 30 leguas que din ter andado para chegar ao santuario, poderían levar a pensar que a súa procedencia fose a vila lucense de Portomarín. Porén, sabemos que nas Ermidas denominábase portenses a todos os habitantes do partido petitorio de Los Puertos, que abarcaba tanto a zona de Sarria-Lugo, na que se atopa Portomarín, como toda a costa sur galega e a provincia de Ourense ata Ribadavia, e na Egloga de Virgine Deipara, representada no colexio dos xesuítas de Monterrei en 1581, as mencións a Los Puertos parece que se refiren tamén de maneira xenérica ao territorio costeiro do sur de Galicia. 
seguro que, polas súas características e extensión, converten a Luis de Losada nun autor destacado na literatura galega dos Séculos Escuros ${ }^{21}$, sendo ademais, segundo varios indicios, autor tamén dos Versos gallegos a nuestra Señora de Reza atribuídos ata agora a José Noguerol e Camba.

\author{
Ilustrísimo señor, \\ oy a miña Musa toda, \\ say á praza á pubricar \\ as honras da nosa Aurora \\ de Reza, que é nosa imagen \\ que en iste pobo se adora \\ por patroa singular, \\ por alegre, por señora, \\ por galega, por paisana, \\ por ser de Ourense a alma toda. \\ Pero sepa su insolencia, \\ que diz que toda esta obra \\ se a de ver polo escrivano \\ eo fiscal botarlle a copra. \\ Eu apelo a súa merced \\ de sentencia tan odiosa, \\ que o escrivano é meu contrario, \\ e será a relación torta.
}

\footnotetext{
${ }^{21}$ A importancia da figura de Luis de Losada foi sempre salientada polos autores xesuítas e polos estudosos da historia da filosofía en Espańa, pero non tanto nas historias da literatura. No que se refire á literatura española, García Boiza destacou en 1915 o papel do lucense no renacemento literario salmantino da primeira metade do século xviII e reivindicou para Losada "un puesto en la historia de nuestras letras", reivindicación que fixo súa J. L. Cortina Iceta en 1981 nun traballo fundamental para achegarse ao coñecemento da personalidade literaria de Losada e da súa traxectoria vital. O Padre Losada foi un escritor prolífico e polifacético, autor de máis de oitenta obras (case todas publicadas con pseudónimo), entre elas notables e moi populares tratados e manuais de filosofía, exexese bíblica, poesías, sátiras varias e pezas teatrais. Foi unanimemente eloxiado polos seus contemporáneos (entre eles os galegos Yebra e Feijoo), que loaron o seu dominio do latín, do francés, do italiano e do español, a súa variedade métrica e a habilidade para manexar tanto rexistros serios e cultos como cómicos e populares.
} 
Que istes versos sejan meus se ten por cousa notoria, e se mos apunta mal, de poeta perdo a groria. Do fiscal Dios che me libre, si acaso a maldita solta se con quatro ollos me mira cando pra matar dous sobran. Confiado no agasallo que a mińa Musa medrosa espera topar en todos, empezo. Baya de Loa.

Virgen de Reza, sol puro que alumbrache a España toda, dándonos en Gabrieliña un menińo, que en Europa a de assombrar ós reveldes, e pisar as súas coroas, que como ladrós furtadas ten, sin dalas a quen tocan. A de recobrar tamén a Virgen bella, e dar honra á fe de Noso Señor, e aumentará con tal sona, que hasta o fin do mundo todo chege a súa fama heroica.

E despois destas ventajas, e despois destas vitorias, veña ao noso grande Apóstol, beyjar os pés, e, de volta, veña a Ourense a vervos, Virgen, veña a darbos gracias, moytas, de todas estas mercedes, que en cifra ban eiquí postas. 
E desde agora convido

os presentes para outra obra

Como esta, se é que vivimos,

se nón, quedaybos embora.

O poema, en 56 versos de romance octosilábico, inclúese entre os presentados a un certame literario que tivo lugar en Ourense a principios de setembro de 1707 no contexto das festas celebradas na cidade con motivo do nacemento do príncipe Luis Jacobo, fillo de Filipe V e María Luisa de Saboia, e futuro Luís I. A obra atribúese na edición de 1708 (Butrón y Múxica / Cossío Bustamante 1708) a "un Autor no conocido, ni dado à luz por mano de D. Joseph Noguerol su mismísimo primo-hermano", o que parece indicar que si era coñecido para o editor, que sabía que José Noguerol e Camba era só un home de palla, familiar do verdadeiro autor. Así parecen telo entendido tamén os primeiros editores modernos da peza (Antonio de la Iglesia en 1886, Carré Aldao en 1903 e 1911...), que se limitan a reproducir o parágrafo introdutorio ao poema na edición do Clarín de la Fama sen atribuílo expresamente a Noguerol.

Porén, o propio Antonio de la Iglesia na súa Memoria dos Xogos Florais coruñeses de 1861, aínda que fala dun autor incógnito e non inclúe o poema á Virxe de Reza no Mosaico, afirmou que "la descripción de dichas fiestas nos revela que [o autor] fué D. José Noguerol y Camba, adalid en aquellas justas”, afirmación que fixeron súa Benito Varela Jácome (1951: 181) e Xosé María Álvarez Blázquez (1959: II, 273-275), interpretando que o autor era realmente D. José Noguerol e Camba, o cal, quizais por escribir en galego, esconderíase como primo irmán dun anónimo escritor ${ }^{22}$.

${ }^{22}$ Dende Álvarez Blázquez, a atribución do romance a Noguerol é practicamente unánime, aínda que algúns autores como José Hervella (2011: 354), á vista da incongruencia da nota introdutoria, considérano "de autor desconocido". De D. Joseph Antonio Noguerol e Camba sabemos que foi un cabaleiro ourensán, emparentado cos Losada, que participou nas guerras da independencia portuguesa e era titular dun morgado, fundado por Dona Catalina de Velosillo e Ulloa, que incluía varias herdades, e un oficio de escribán do concello de Ourense. Noguerol foi rexedor da cidade e Alférez Maior, cargo en virtude do cal alzou os pendóns e presidiu en 1700, por delegación de D. Andrés de Gayoso Ozores e Soutomaior, a cerimonia ourensán de proclamación de Filipe V. En 1713 foi desterrado a 10 leguas de distancia de Ourense por abusos cometidos no exercicio das súas funcións. Fóra dos dous poemas presentados co seu nome ao certame de 1707 non temos máis noticias da súa actividade literaria, se é que tivo algunha. 
Creo, con todo, que a cousa é á inversa, e que Noguerol é só unha pantalla do verdadeiro autor, o cal é moi probablemente o Padre Luis de Losada. Iso non pode estrañar coñecendo a teima heterónima do xesuíta quirogués e a súa afección aos xogos de ocultación nos seus escritos ${ }^{23}$, e tampouco desentoa na edición do Clarín de la Fama, na cal aparecen varios poemas coa autoría cifrada no texto, nin no certame literario, ao cal parece que se presentaron tamén outras composicións por medio de autores interpostos (o editor, P. Butrón, acusa a Tomás Francisco de Losada, parente do Padre Luis e Colexial Maior do arcebispo de Salamanca, de escribir as composicións presentadas a nome do seu pai, o rexedor José de Losada, e do seu irmán menor, o comandante de cabalería Diego de Losada).

Creo, ademais, que o propio Butrón y Múxica nos proporciona as claves da autoría do poema á Virxe de Reza no Vexamen de estira, y afloxa, no cal glosa as composicións presentadas ao certame e critica xocosamente os seus autores, el mesmo incluído, aínda que poñendo as burlas en boca dun sancristán. E así, ao referirse a Noguerol di: "el Señor D. Joseph Noguerol y Camba, que con su Romance Gallego es Camba, y Campa tiene excelente discurso, y todo lo haze bien". Campa, resaltado en cursiva na impresión, é xogo de palabras con Prada, o segundo apelido de Luis de Losada, e cando Butrón comenta o poema en castelán que o devandito Joseph Noguerol presentou ao Quarto assumpto do certame, búrlase duns versos referidos a Filipe V (Siendo Padre piadoso, / Docto,

${ }^{23}$ A teima de Losada, que usou unha trintena de firmas distintas nos seus escritos, dificulta o labor de catalogación da súa obra (ao Padre Uriarte débese o primeiro intento de catalogación desta, completada por García Boiza, Cortina Iceta, Aguilar Piñal e Díaz Díaz). Non se sabe por que tiña o P. Losada a obsesión de ocultar o seu nome e, segundo o seu discípulo o Padre Larramendi, só por obediencia aos seus superiores na Compañía publicou co seu verdadeiro nome o Cursus philosophici Regalis Collegii Salmanticensis, in tres partes divisus (1724) e a súa introdución, as Institutiones dialecticae, popularmente cońecidas como Summulae (1721). Aínda que Losada publicara antes algunha obra sen ocultar a súa autoría (por exemplo a Alegórica Expresión de la Verdad sobre el horóscopo feliz del Serenisimo Luis Fernando, Principe de las Españas de 1707), é certo que a práctica totalidade da súa produción literaria se publicou con pseudónimos, e se coñecemos a autoría de moitas obras é grazas ás mencións dos seus discípulos e compañeiros ou polas indicacións dos copistas nos manuscritos. No caso de La Juventud triunfante, na portada da primeira edición (Salamanca, 1727) figura como autor "Un ingenio de Salamanca", pero na Fe de erratas da impresión valenciana de 1750, morto xa Losada, afírmase: "Este Libro intitulado La Juventud Triunfante, representada en las Fiestas [...] su Autor el P. Luis de Losada de la Compañía de Jesús", e xa no Dictamen da primeira edición o P. Butrón y Múxica dicía ironicamente: "No sé que ayre me da de que conozco al Author. No quiere, que le conozcan; pero quien lea aquí tres renglones dirá que es suyo el papel”. 
afable, benigno y religioso), dicíndolle ao autor deles: “¿Aun no Principiamos, y ya Padreamos?”, en evidente alusión, penso eu, á inminente ordenación sacerdotal de Losada (cursivas e maiúsculas no impreso) ${ }^{24}$.

Por outra banda, hai indicios da participación de Losada na composición doutros textos en castelán para os festexos ourensáns de 1707, aínda que non se nomee na edición. É probable que o prólogo de Butrón Al discípulo, y no al lector de ninguna de las maneras estea dirixido a Losada, que debeu de ser alumno seu no colexio de Santiago entre 1701 1704, e creo que as Coplas al principe Luis (pp. 97-98) son obra de Losada ${ }^{25}$, e se cadra tamén a Loa (pp. 74-94) ${ }^{26}$.

Cabe tamén a posibilidade dunha autoría xesuíta para o Entremés de los gallegos (ca. 1640) conservado nunha colección de entremeses e bailes procedente da biblioteca do Duque de Osuna (hoxe na Biblioteca Nacional, Ms. 15403, fols.

${ }^{24}$ A principios de setembro de 1707, Losada, con 26 anos, estaba probablemente en Galicia despois de rematar o terceiro curso dos seus estudos de teoloxía en Salamanca, e na matrícula do curso 1707-1708, derradeiro da carreira, xa aparece como sacerdote.

${ }^{25}$ As coplas recitáronse nun sarao nocturno o mércores día 7 de setembro, sétimo do novenario de festexos polo nacemento do príncipe Luis Jacobo, e xogan co nome do príncipe festexado, Luis/Lilio/Lis, ao que Ourense lle mostra a súa fidelidade. Non consta na impresión o nome do seu autor pero creo que poden ser do P. Luis de Losada, xa que o seu Pranto galego pola morte de Luis I de España (Salamanca, 1724) parece antífrase consciente das coplas ourensáns, e nas dúas composicións empréganse similares metáforas florais e cultismos (zafir, pensil), ademais de nomearse en ambas o Miño e o Sil. Evidentemente, cabe a posibilidade de que as coplas sexan obra de Butrón e que Losada, en 1724, se inspirara nelas para compoñer o seu Pranto, pero Butrón non dá ningún indicio no Clarín de que a composición de 1707 sexa súa, como adoita facer coas que o son, e no prólogo di con sorna: "Las Coplas están muy malas / Son de vn Cuerbo á mi entender", aludindo á oposición cisne/corvo e probablemente tamén ao hábito negro xesuíta.

${ }^{26}$ A Loa, representada o 5 de setembro, é un resumo dos acontecementos da guerra de Sucesión desde os seus comezos ata a entón recente vitoria filipista na batalla de Almansa, e un eloxio da Monarquía borbónica, de Filipe V e do recentemente nado príncipe Luis. Cadra cunha atribución a Losada o estilo da peza e a súa estrutura (música, personaxes alegóricos mesturados con outros cómicos...), o seu filipismo militante (coñecido en Losada e a súa familia), e os eloxios a Galicia (Mueran los Reveldes [portugueses], y triumphe Galicia!). Tales características aparentemente non concordan coa personalidade literaria e a galegofobia de Butrón y Múxica, que podería ser autor da obra, e si coa de Losada, pero en calquera caso parece que se trata dunha peza xesuítica e sabemos que o colexio ourensán estivo fortemente implicado na organización dos festexos e na dimensión literaria destes. O colexio foi a sé do certame literario convocado ("Señalose por palestra el Colegio de la Compañía de Jesús, que, siendo taller de ingenios, no pudieran, sin injuria, examinarse los de Orense en otra oficina”), e xesuíta foi o Padre Butrón, encargado da edición das obras presentadas ao dito certame e da descrición das festas, edición que lle dedica ao P. Balthasar Rubio Sánchez, provincial de Castela e confesor da raína María Luisa de Saboia. 
96v-98r), unha peza breve (133 liñas) escrita practicamente na súa totalidade en galego, aínda que imperfecto ${ }^{27}$.

Non consta o lugar no que se representou, pero unha referencia no texto "ao mismo Conde de Lemos" leva a pensar que puido ser Monforte, evidentemente nun entreacto dunha obra maior, quizais a Comedia del Siglo centenario de la Compañía de Jesús, que se representou na vila de Lemos os días 28 e 29 de maio de 1640. A autoría dun xesuíta parece posible, xa que o galego que nel se utiliza, aínda que deficiente e corrupto pola copia, é claramente intencional e non paródico, trazos habituais no teatro dos xesuítas en Galicia, a diferenza doutros textos teatrais espańois da época nos que aparece tamén o galego pero caricaturizado ${ }^{28}$. Cadra tamén cun posible autor xesuíta o final da peza con música e danzas, mencionadas na documentación sobre a representación monfortina de 1640, na cal houbo bailes e tamén "había músicos que cantaban y otros de guitarra y arpa".

O tema do Entremés son os celos que Dominga ten do seu home Toribio e de Fila pero, como corresponde ao xénero, non hai drama. $\mathrm{O}$ ton é humorístico e acaban cantando cos músicos e bailando un j $A y$, ay, ay! Como mostra da lingua e da grafía empregadas na obra, pode valer este soliloquio de Dominga no comezo da peza:

$\begin{array}{ll}\text { Sale Domin[ga]: } & \text { O mala rayba le beña } \\ & \text { ao primero que los celos } \\ & \text { trago ao mundo, pues me traren } \\ & \text { por aquestos bericuetos! } \\ & \text { El meu ome, as meas beziña }[\mathrm{s}] \\ & \text { me an digto que beue o bento }\end{array}$

${ }^{27}$ Cómpre lembrar que da biblioteca do Duque de Osuna procede tamén o manuscrito do Entremés famoso sobre la pesca del rio Miño ou Contenda dos labradores de Caldelas de Gabriel Feixoo de Araúxo (1671).

${ }^{28}$ Son relativamente frecuentes os diálogos paródicos en galego incluídos en obras teatrais españolas e portuguesas dos séculos XVII-XVIII, e numerosos tamén os entremeses e bailes de galegos nos que se utilizan estribillos en lingua galega (por exemplo, o Baile de los gallegos (BnE, Ms. 14851, fols. 112-113): Ea galeguiños, ea / dad nova enbidia a Castela). Hai tamén algunhas pezas breves nas que aparece o galego nunha porcentaxe elevada dos diálogos, pero non son obras compostas en Galicia nin pensadas para representarse nela, senón caricaturas burlescas de autores foráneos montadas sobre unha galeguización do español e de formas dialectais asturianas e leonesas, como sucede, por exemplo, no entremés de mediados do século XVIII editado por J. L. Pensado e titulado Los gallegos, obra dun tal Juan de Dios (BnE, MSS. 14516/59), ou na Tonadilla siguiendo la idea del sainete 'Hospicio de vergonzantes' do asturiano Tomás Feijoo (século xviII, BnE, MSS. 14094, fols. 11r-12v). 


$$
\begin{aligned}
& \text { por Fila, e miray porque } \\
& \text { no e mays fermosa por certo } \\
& \text { que eu, porque se pringa } \\
& \text { facendose a puro unguento } \\
& \text { branca. De aquesa manera } \\
& \text { nebe eu me ubera feyto. } \\
& \text { Si le collo en algun furto } \\
& \text { por Santiago que le teño } \\
& \text { de pelar todas as barbas! } \\
& \text { Uy, deuierame perco } \\
& \text { que Fila e Toribio bienen! } \\
& \text { Escondome, aqui obirelos } \\
& \text { sin que ninguno me bexa. }
\end{aligned}
$$

Ata aquí chega o corpus cońecido na actualidade de textos en galego no teatro dos xesuítas. Non é moito, pero si moito máis do que ata hai poucos anos poderiamos imaxinar nesa época, e resulta en principio sorprendente que na maior parte dos textos teatrais conservados apareza o galego. Non teño suficiente formación filolóxica para facer unha análise lingüística do galego que neles se utiliza, e só sinalo que cómpre ter en conta que os manuscritos conservados son copias de amanuenses que falaban castelán, e algúns probablemente copia de copia, polo cal os textos teñen con moita probabilidade un grao alto de corrupción.

Hai casos nos que é difícil distinguir nos manuscritos entre galego e portugués, e aínda entre portugués e castelán, xa que os textos que temos están mediatizados polos usos lingüísticos dos copistas, que poden levarlles a preferir as formas gráficas do portugués ás do galego, e viceversa. De feito, na mesma peza detéctanse vacilacións como sucede na Égloga de Monterrei (muy, moi e mui; mesmo e mismo; mellor e millor; entre, antre e antra...). Podería tratarse, fóra as corrupcións dos manuscritos e a carencia de modelos, dun desexo dos autores e dos copistas de preservar variantes dialectais, pero non podo ir máis alá neste asunto non sendo especialista. O que si intentarei é facer unha valoración histórica e literaria da presenza do galego no teatro xesuítico e un esbozo de interpretación sociolingüística. 


\section{O GALEGO DOS XESUÍTAS NO CONTEXTO DOS SÉCULOS ESCUROS}

É coñecido que hai algúns indicios da existencia do que hoxe se denominaría conciencia lingüistica na Galicia dos séculos XvI-XviII. Consta en primeiro lugar, cronoloxicamente, o que parece desgusto do autor teatral de Santiso, Xerónimo Bermúdez de Castro, dicindo cara a 1575 que escribira as súas traxedias Nise lastimosa e Nise laureada "en la lengua castellana, aunque agena de la mia natural"29, e sábese tamén que D. Diego Sarmiento de Acuña, I Conde de Gondomar, empregaba o galego na súa correspondencia con amigos e familiares, e que Diego Sarmiento de Soutomaior escribiulle en 1605 en galego dicindo: "e mais que fixese ysto nesta lingoaje, pois é de vosa mercé tan estimada” (Álvarez Blanco / Rodríguez Montederramo 2004: 260, 282) 30. $^{30}$

Probablemente, a testemuña máis clara da existencia nas elites cultivadas e na nobreza galegas dos séculos XVI-XVII de certa conciencia sobre o menoscabo do galego é a do profesor da Universidade compostelá Ioan del Río y Otero, que se laia en 1697 pola "nosa lingua esquecida nomais, que por ser galega" ${ }^{31}$. Os casos citados, e algúns outros similares, parece claro que proban a supervivencia do galego como lingua familiar na nobreza galega e nos círculos intelectuais de Galicia nos séculos XVI-XVII —e tamén o seu desprazamento como lingua culta en favor do castelán-, e no caso da Universidade pódese entender se temos en conta que nesa época os colexios universitarios composteláns de Santiago Alfeo e de San Xerónimo eran das poucas institucións galegas nas que o acceso se reservaba para os naturais do país, polo que se converteron en baluarte da pequena nobreza e da burguesía culta de Galicia. Cabe pensar, entón, que poderían reflectir un interese de clase que pretendía garantir os privilexios dalgúns grupos sociais galegos fronte a posibles invasións de colexiais ou de funcionarios foráneos, ou un interese de caste mesturado con conciencia lingüístico-evanxelizadora como o que manifesta

${ }^{29}$ Primeras tragedias españolas de Antonio de Silua..., Francisco Sánchez Impressor, Madrid, 1577, Carta del auctor [p. 1].

${ }^{30}$ Outro membro da nobreza galega do século xvi que empregaba o galego na súa correspondencia foi Pedro Álvarez V de Soutomaior “o parricida” (véxase Álvarez Blanco / Xove Ferreiro 2013).

${ }^{31}$ Fiestas Minervales, y aclamación perpetua de las Musas..., p. 31. Del Río era probablemente de Boiro, e gańou co seu romance o primeiro premio no segundo asunto do certame, unha medalla de ouro do Apóstolo. A súa é a defensa do galego máis explícita coñecida ata o P. Sarmiento. 
o cabido de Santiago cando en 1597 se queixa do arcebispo Sanclemente por teren adxudicado os "mexores beneficios [...] no solo a los de reinos extraños pero a los que penetibus ignoraban la lengua gallega”.

Non parece, porén, que fora ese o interese dos xesuítas, maioritariamente non galegos como xa sinalei. O emprego do galego no teatro xesuítico enlaza cunha tradición moi estendida no teatro dos séculos XVI-XVIII, non só no escolar, de utilización das linguas vernáculas e de variantes dialectais como elemento caracterizador da procedencia social e/ou xeográfica dos personaxes, chegándose incluso á [re]creación dun dialecto artificial como o saiagués, expresión literaria culta dunha suposta linguaxe pastoril e popular. Este último utilízase as máis das veces cunha intención cómica que, no teatro dos xesuítas en Galicia, tamén atopamos ${ }^{32}$.

Hai ademais, creo eu, moito de exercicio literario e de divertimento lingüístico por parte dos autores das obras, que empregan o galego e o portugués principalmente por motivos estéticos, como un recurso literario máis e coa mesma intención pola que xogan con diferentes estrofas, metros e rimas. Penso que pode haber tamén algo do que hoxe chamariamos enxebrismo ou folclorismo, e entendo que non pode ser casual que a práctica totalidade dos textos xesuíticos en galego sexan romances octosilábicos, metro popular por antonomasia, pero non vexo en ningún caso intención paródica no uso do galego por parte dos autores xesuítas.

Pola contra, nalgúns deles o que hai é un certo ton reivindicativo da lingua galega, e de Galicia e os seus habitantes. O caso máis evidente é o do Entremés del portugués, no cal se inverte o tópico do galego torpe e burlado do teatro áureo español, sendo nel o gallego quen demostra superioridade física e de enxeño fronte ao sevillano, o francés e o portugués. O seu autor, o Padre Losada, foi o mellor expoñente da defensa de Galicia e da lingua entre os xesuítas pero non chega nin remotamente ao nivel do seu discípulo Manuel de Larramendi no caso do éuscaro ou ao do Padre Pere Gil Estalella no catalán.

${ }^{32}$ Por exemplo, no Entremés de los pastores, que se representou en 1581 nun entreacto da Égloga de Monterrei, os personaxes dialogan en castelán, pero os pastores Lorenzo e Toribio, prototipo este de rústico comellón e bebedor, empregan ás veces con intención cómico-caracterizadora léxico saiagués (estruégamo, quantis, endeletijo...), ou galego (polido, canada...), e galeguismos gramaticais (¡habríamos de faltar!). Véxase a miña edición en González Montañés (2008). 
Boa parte dos textos literarios en galego que conservamos dos Séculos Escuros comparten cos teatrais dos xesuítas un carácter anecdótico no emprego da lingua e a utilización dun rexistro lingüístico popular, aínda que hai tamén no galego medio testemuños intencionadamente cultos, tanto na obra dos xesuítas (o Pranto galego pola morte de Luis I de España de 1724) como na doutros autores: por exemplo, o Soneto de Monterrei (ca. 1530-1540), a Canción en loor de don Diego das Mariñas (ca. 1594), os dous sonetos dedicados á morte de Margarida de Austria (ca. 1612), ou as Cincuenta décimas contra don Diego Zernadas (ca. 1770) recentemente publicadas por Xosé A. Fernández Salgado (2017).

No caso do Pranto, obra moi probable do xesuíta Luis de Losada, como demostraron Ramón Mariño e Damián Suárez, consta que o autor se lamentou na presentación da súa composición da carencia de modelos literarios en galego, segundo el por terlle cedido, de puro cortés, o posto ao castelán como lingua culta aun en su patrio suelo:

Añadiò [o poeta] que la Lengua Gallega de puro cortès no se avia cultivado tanto, como pudiera, por ceder el lugar, aun en su patrio suelo, à la reynante Castellana; pero que no obstante explicaria el mismo pensamiento con algunas tiernas expresiones, que las Musas pudiessen $\operatorname{adoptar}^{33}$.

Similar lamento pola falta de modelos, e proba do aprecio dos xesuítas polo galego, é o do Padre Juan Álvarez Sotelo na súa Historia general del Reino de Galicia (Monterrei, ca. 1700) falando do Lenguaje de Galicia:

La lengua gallega [...] es tan copiosa que a veces para una cosa tiene muchas palabras vivamente esplicadas, griegas unas y latinas otras, propias unas y otras metafphoricas maravillosamente aplicadas. Es muy suave y tierna, elegante y grave, como hija de las dos mejores del mundo [o grego e o latín] y por la sinalefa y síncope mucho mas breve que la espańola. No se halla pura sinó entre los plebeyos que nunca salieron del ámbito de su aldea ni leyeron libros espańoles, por que los nobles hablan la castellana como predominante en Espańa, y los que salieron de Galicia, o saben leer, mezclan vocablos castellanos y estragan la pronunciación gallega.

33 Oracion Funebre con que el Real Colegio de la Compania de Jesus de Salamanca... [pp. 37-38]. 
Como no se imprimen libros en ella [...] no tiene el curioso por donde hacer perfecto concepto de ella: mas podrá hacer alguno por la portuguesa quitándole aquella afectación hinchada con que pronuncian los lusitanos, por que la lengua portuguesa es la misma gallega llevada a la Lusitania por los gallegos... ${ }^{34}$.

${ }^{34}$ Libro I, cap. 25, Mss. BnE, 2757, fols. 24v-26v, copia do BRAH, C-100. Publicada parcialmente en Galicia: revista universal de este reino (o cap. 25 no n. ${ }^{\circ} 1$ (1860), p. 7). 


\section{REFERENCIAS BIBLIOGRÁFICAS}

Alonso Asenjo, Julio (2018): La Égloga de Virgine Deipara: estudio y edición. Santiago de Compostela: Universidade de Santiago de Compostela. <https://doi.org/10.15304/9788416954742>.

Álvarez Blanco, Rosario / Xosé Luís Rodríguez Montederramo (2004): «Escrita epistolar en galego: a correspondencia de Don Diego Sarmiento de Acuña, I Conde Gondomar (1567-1626) [I]», Boletín da Real Academia Galega 365, 254-291.

Álvarez Blanco, Rosario / Xosé Luís Rodríguez Montederramo (2005): «Escrita epistolar en galego: a correspondencia de Don Diego Sarmiento de Acuña, I Conde Gondomar (1567-1626) [II]», Boletín da Real Academia Galega 366, 225-303.

Álvarez Blanco, Rosario / Xosé Xove Ferreiro (2013): «Cartas que cruzan o Miño. Correspondencia con don Pedro Álvarez V de Soutomaior, falsificador (1527)», en Rosario Álvarez / Ana Maria Martins / Henrique Monteagudo / María Ana Ramos (eds.): Ao sabor do texto. Estudos dedicados a Ivo Castro. Santiago de Compostela: Universidade de Santiago de Compostela, 29-55.

Álvarez Blanco, Rosario / González Seonne, Ernesto X. (2015): «O romancillo da cea do cordeiro, texto galego do século xviı", en Francisco Dubert / Gabriel Rei-doval / Xulio Sousa (eds.): En memoria de tanto miragre. Estudos dedicados ó profesor David Mackenzie. Santiago de Compostela: Universidade de Santiago de Compostela, 21-40.

Álvarez Blázquez, Xosé María (1959): Escolma de poesía galega. 2 vols. Vigo: Galaxia.

Busto Cortina, Xuan Carlos (2015): «Un volume de testos de poesía asturiana de reciente apaición», en Revista de Filoloxía Asturiana 15, 33-56. <https://doi.org/10.17811/rfa.15.2015.33-56>.

Butrón y Múxica, Joseph Antonio / Diego de Cossío Bustamante (1708): El Clarín de la fama y cithara de Apolo, con métricos rasgos a las reales fiestas que en el felicissimo nacimiento de el Principe N. Señor D. Luis Jacobo Primero el deseado executó la... ciudad de Orense. Santiago de Compostela: Imp. de Antonio de Aldemunde.

Cabada Castro, Manuel (2015): Crónica de un encuentro-desencuentro cultural. Análisis antropológico de las misiones populares jesuiticas en Galicia. Madrid: Universidad Pontificia Comillas.

Cortijo Ocaña, Antonio (2001): «Un texto galego descoñecido do século xvi a Comedia de la invención de la sortija da Bancroft Library (Berkeley)", Anuario de Estudos Literarios Galegos, 17-49.

Cortijo Ocaña, Antonio / Miguel Zugasti Zugasti (2016): Adiciones al corpus dramático español del siglo XVI. La 'Comedia de la invención de la sortija', partes I y II (Monforte de Lemos, 1594). Pamplona: EUNSA.

Cortina ICETA, Juan Luis (1981): El siglo XVIII en la pre-Ilustración salmantina. Vida y pensamiento de Luis de Losada (1681-1748). Madrid: Instituto Enrique Flórez-CSIC.

Cristóbal Hornillos, Rubén (2010): La sátira mordaz de Butrón y Mújica. Edición de la poesía y el teatro de un poeta bilbilitano en el ostracismo. Calatayud-Zaragoza: Centro de Estudios Bilbilitanos de la Institución Fernando el Católico.

Fernández Salgado, Xosé A. (2017): Cincuenta décimas contra don Diego Zernadas. Edición e estudo dun novo texto en galego do século XVIII. Santiago de Compostela: Laiovento.

Fiestas Minervales, y aclamación perpetua de las Musas, a la inmortal memoria de el Ilustrissimo, y Excelentíssimo señor D. Alonso de Fonseca el Grande [...] que afectuosamente las consagra [... [ al Señor Conde de MonteRey, su protector [...] por mano de el Doctor D. Ioseph Varela y Vasadre, Retor de dicha Universidad. Santiago de Compostela: Imprenta de Antonio Frayz Piñeiro, 1697. 
García Boiza, Antonio (1915): Datos para el estudio de la personalidad literaria del Padre Luis Losada, S. J. Conferencia leida en la Universidad de Salamanca. Salamanca: Imp. de Calatrava, a cargo de Manuel P. Criado.

González Montañés, Julio I. (2007): «La Egloga de Virgine Deipara y el teatro de los jesuitas en Galicia en la Edad Moderna", Anuario del Instituto Ignacio de Loyola / Loiolako Inazio Institutuen Urtekaria 14, 247-286.

González Montañés, Julio I. (2008): «El Entremés de los pastores de la Egloga de Virgine Deipara, pieza de teatro jesuítico representada en el Colegio de Monterrei (Ourense) el 8 de diciembre de 1581. Edición y estudio", TeatrEsco. Revista del Antiguo Teatro Escolar Hispánico 3. <http://parnaseo.uv.es/ars/teatresco/ Revista/Revista3/Entremes_de_los_pastores_en_la-Egloga_de_Virgine_Deipara.pdf >

González Montañés, Julio I. (2014): Teatro en Galicia. Noticias de representaciones hasta 1750. <https:// goo.gl $/ \mathrm{nhXCmE}>$.

GonzÁlez Montañés, Julio I. (2016): «El Entremés del portugués, pieza teatral jesuítica en gallego del siglo xviII. Noticia del manuscrito, edición y estudio", en Taller de TeatrEsco. Valencia: Parnaseo-Universidad de Valencia. <http://parnaseo.uv.es/Ars/teatresco/Taller/Entremes_del_portugues.pdf>

Hervella V́́zquez, José (2011): «Al séptimo asunto. Versos gallegos a Nuestra Señora de Reza», Porta da Aira. Revista de historia del arte orensano 13, 351-354.

Mariño Paz, Ramón / Damián SuÁrez VÁzQuez (2012): «Luís de Losada e o pranto galego pola morte de Luís I de España (1724)», Boletín da Real Academia Galega 373, 325-360.

Oracion Funebre con que el Real Colegio de la Compania de Jesus de Salamanca, celebro las Reales Exequias de nuestro Joven Monarca D. Luis Primero de este Nombre, y alguna Noticia del aparato lugubre que se dexaba ver en la Iglesia de dicho Real Colegio. Dalo a luz D. Martin de Lardizaval y Elorza, Colegial Huesped en el Colegio Viejo de San Bartholome Mayor de Salamanca. Con licencia del Señor Maestre-Escuela. Salamanca [1724].

Pacheco y Troncoso, Juan (1715): Fiestas Compostellanas con que la siempre grande, muy noble y leal ciudad de Compostella celebró la canonización de Máximo Pontifice San Pio Quinto, cuchillo de los Herejes, Terror de los Sarracenos. Santiago de Compostela: Antonio Pedache.

Pascual Barea, Joaquín (2009): «El Diálogo de la Concepción de Nuestra Señora del Padre Bravo a la luz de los libros De Arte Poetica y De Arte Oratoria de Bartolomé Bravo», en T. Arcos Pereira / J. Fernández López / F. Moya Del BAÑo (eds.): Pectora mulcet. Estudios de retórica y oratoria latinas. Vol. II. Logroño: Instituto de Estudios Riojanos, 1143-1155.

RIVERA VÁzQuez, Evaristo (1989): Galicia y los jesuitas. Sus colegios y enseñanza en los siglos XVI al XVIII. A Coruña: Fundación Pedro Barrié de la Maza.

Rivera VÁzquez, Evaristo (2006): El sorprendente colegio de Monterrei. Madrid: Compañía de Jesús-Provincia de Castilla.

Valdivia, Luis de (1932-1933): "Colegios de los Jesuitas en Galicia. Colegio de Monterrey», en Boletín de la Comisión Provincial de Monumentos Históricos y Artísticos de Orense 204 (1932), 348-356; 206 (1932), 397-404; 207 (1932), 425-428; 208 (1933), 25-29.

Varela Jácome, Benito (1951): Historia de la literatura gallega. Santiago de Compostela: Porto y Cía Editores.

Yebra, Jacinto Bernardo de (1748): Breve noticia de la vida, prendas y virtudes del Padre Luis de Lossada. Salamanca: Antonio Joseph Villargordo y Alcaráz. 